\title{
Integrative effects of no-tillage and straw returning on soil organic carbon and water stable aggregation under rice-rape rotation
}

 \\ ${ }^{1}$ Key Laboratory of Arable Land Conservation (Middle and Lower Reaches of Yangtze River), Ministry of Agriculture, Huazhong \\ Agricultural University, Wuhan 430070, China. *Corresponding author (daisyh@mail.hzau.edu.cn).
}

Received: 13 November 2017; Accepted: 7 March 2018; doi:10.4067/S0718-58392018000200205

\begin{abstract}
No-tillage and straw returning are important practices for preserving and improving soil quality for the sustainable management system. The experimental field was established in 2007 with conventional tillage (CT), conventional tillage with straw returning (CTS), no-tillage (NT), and no-tillage with straw returning (NTS) practice in rice (Oryza sativa L.)rape (Brassica napus L.) cropping system. The soil samples were collected in 2013-2015 from 0-20 and 20-40 cm depth to investigate the effects on soil organic C (SOC), water-stable aggregation $(>5,5-2,2-1,1.0-0.5,0.25-0.5$, and $<0.25$ $\mathrm{mm}$ ), and their stability in paddy soil of the central China. In the last year (2015), the integrative use of no-tillage and straw returning significantly increased SOC content and contribution of the macroaggregates in $0-20 \mathrm{~cm}$ and microaggregates in 20-40 cm depth. Compared with CT, SOC content, mean weight diameter (MWD), geometric mean diameter (GMD), and fractal dimensions (FD) under NTS were increased 25\%,21\%, 19\%, and 12\%, respectively, in the 0-20 cm depth. In $20-40 \mathrm{~cm}$ depth, the soil micro-aggregates were higher under CTS treatment. Percentages of macroaggregates and microaggregates under NTS were increased $60 \%$ and $40 \%$ in the $0-20 \mathrm{~cm}$ depth. The SOC had positive linear relationship with MWD, GMD , > 5, 2-5, 1-2, and 0.25-0.5 mm aggregates. Thus, long-term combine use of NT with straw returning practices significantly improved SOC and water-stable aggregation. No-tillage and straw returning appeared to be promising and sustainable strategies to conserve SOC sequestration and stable soil aggregates in rice-rape cropping system.
\end{abstract}

Key words: Brassica napus, conventional tillage, no-tillage, Oryza sativa, soil organic carbon, soil water-stable aggregation, straw returning.

\section{INTRODUCTION}

The soil organic C (SOC) plays an imperative role in regulating soil ecological and $\mathrm{C}$ cycling processes in the global scale (Chen et al., 2014). The soil management practices are considered essential to conserve soil quality (Kahlon et al., 2013), and can greatly affect the composition and stability of SOC through plough layer (Stone and Schlegel, 2010; Bhattacharyya et al., 2012; Ghosh et al., 2016). Conventional tillage (CT) could reduce the SOC content and accelerate SOC oxidation rate, probably due to the disturbance of soil aggregates and the increase of the soil aeration (Gathala et al., 2015). A global database of 67 long-term research trials reported that a change from conventional tillage (CT) to no-tillage (NT) can sequester about $57 \pm 14 \mathrm{~g} \mathrm{C} \mathrm{m}^{-2} \mathrm{yr}^{-1}$, with the SOC sequestration rate expected to reach the peak within 5-10 $\mathrm{yr}$ after conversion from CT to NT practices (West and Post, 2002). Moreover, Six et al. (2002) reported a general trend to increase the SOC content about $325 \pm 113 \mathrm{~kg} \mathrm{C} \mathrm{ha}^{-1} \mathrm{yr}^{-1}$ under NT as compared with CT plots. 
The continuous long term no-tillage systems in the surface layers may provide an incomplete view of changes occur in soil profile (Blanco-Canqui et al., 2011). Angers and Eriksen-Hamel (2008) found that no-tillage soils had significantly higher SOC than conventional soils at the 0-20 cm layers, but found inverse trend at $21-35 \mathrm{~cm}$ depth. Moreover, Poirier et al. (2009) reported that effects of tillage systems seems to be site specific for related SOC and soil properties. However, the magnitude of NT effects on SOC contents may vary and the variation is affected by regional and environmental factors (Poirier et al., 2009; Martinez et al., 2011), which can permit the further view of NT impressions on soil properties.

The aggregate stability indices can reflect the changing of soil aggregate size distribution and describe soil aggregate distribution status in many studies (Gwenzi et al., 2009; Paul et al., 2013; Zhang et al., 2014). Aggregates comprise both macroaggregates $(>0.25 \mathrm{~mm})$ and microaggregates $(<0.25 \mathrm{~mm})$ in the hierarchical model of aggregate organization as described by Tisdall and Oades (1982). Some studies reported that organic input in soil increased the content of those $>0.25 \mathrm{~mm}$ soil aggregates (Zhou et al., 2007), can increase the content of 0.25-5.00 mm water-stable aggregates in soil (Yang et al., 2012). Sandoval-Estrada et al. (2008) reported that standing residues and chopped residues had better structural stability and a higher proportion of macroaggregates $(>0.25 \mathrm{~mm})$, as well as a significant increase in SOC. Soil aggregation be responsible for physical protection of SOC against rapid decomposition (Blanco-Canqui and Lal, 2004), and soil aggregate formation and stability of soil aggregates is closely linked with SOC storage (Gwenzi et al., 2009).

Central China, one of the major rice and rapeseed producing regions, mainly adopts the rice-rape crop rotation farming system in this region. In this region, long-term data on the SOC contents and soil aggregates stability is scare, only few short term studies has been reported about the SOC and soil aggregation. However, there is lack of knowledge regarding long-term use of NT on soil aggregation and SOC contents under rice-rape cropping system in central China. Therefore, it is necessary to understand the soil aggregates response to different tillage/straw returning management practice in rice-rape cropping system. The interaction among soil aggregate size distribution, SOC contents and aggregate stability indices is still not well understood (Blanco-Canqui and Lal, 2004). Meanwhile, little information is available about whether soil aggregate stability is positively or negatively correlated with soil C (Six et al., 2002; Bhattacharyya et al., 2012). Based on recent literature, it is perceived that less studies have investigated the interactive effects of tillage and straw returning in rice-rape rotation system regarding SOC and water stable aggregation. It was hypothesized that whether NT or CT alone is more effective management in soil aggregation, either NT or CT together with straw returning or crop rotation system could be the sustainable management practices for SOC and stable soil aggregation. Thus, the objectives of current study were (1) to examine the interactive effects of no-tillage and straw returning on SOC and water-stable aggregation under a rice-rape rotation in 0-20 and 20-40 cm depths, and (2) to evaluate the relationship among the SOC and different aggregates $(>5,5-2,2-1,1.0-0.5,0.25-0.5$, and $<0.25 \mathrm{~mm})$ after no-tillage and straw returning practices in rice-rape rotation in central China.

\section{MATERIALS AND METHODS}

\section{Site description and experimental design}

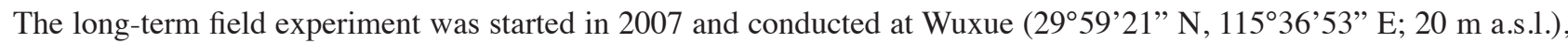
Hubei province in central China, with continuous rice and rapeseed cropping each year. The experimental area was characterized as a humid monsoon subtropical climate zone. The annual average temperature was $16.9^{\circ} \mathrm{C}$, the highest temperature was in July with an average of $29.1{ }^{\circ} \mathrm{C}$ and the minimum was in January with an average of $4.1^{\circ} \mathrm{C}$ (Figure 1). The annual average rainfall was about $1489 \mathrm{~mm}$, the annual mean evaporation was $1361 \mathrm{~mm}$ and domestic frost-free period was about $262 \mathrm{~d}$. The field experiment was arranged randomly with three replicates, each plot size was $15 \mathrm{~m}^{2}(5 \mathrm{~m}$ $\times 3 \mathrm{~m}$ ). Physico-chemical properties of tested soil is presented in Table 1. The experimental field was cultivated with ricerape cropping system. There were four treatments as follows: (1) Conventional tillage (CT), (2) conventional tillage with straw returning (CTS), (3) no-tillage (NT), and (4) no-tillage with straw returning (NTS). There were two main seasons in experimental fields, in which rice was cultivated from June and harvested in October, rape was cultivated from November and harvested in May each year. In the CT and NT plots, rice-rape crops residues were removed and not returned in the field. In NT plots, no soil disturbance occurred except for herbicide, sowing and fertilizer application. In case of CT treatment, the plots were moldboard ploughed twice to $20 \mathrm{~cm}$ depth using a tractor (Shanghai New Holland Agriculture 
Figure 1. Average rainfall and temperature of experimental site during 2013-2015.

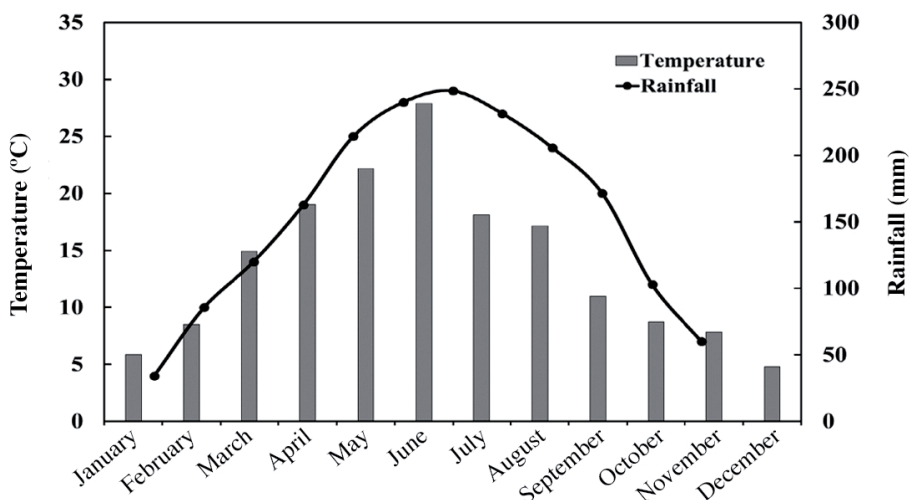

Table 1. Physico-chemical properties of tested soil.

\begin{tabular}{lc}
\hline Soil character & Mean value \pm SE \\
\hline Soil texture & Loam \\
Clay, \% & $17.3 \pm 0.52$ \\
Silt, \% & $42.7 \pm 0.42$ \\
Sand, \% & $39.9 \pm 0.62$ \\
Soil pH & $5.2 \pm 0.02$ \\
Soil organic matter, g kg-1 & $34.1 \pm 0.20$ \\
Total N, g kg-1 & $1.9 \pm 0.01$ \\
Total P, g kg-1 & $0.5 \pm 0.03$ \\
Available P, mg kg-1 & $6.6 \pm 0.10$ \\
Total K, g kg-1 & $21.7 \pm 0.30$ \\
Available K, mg kg-1 & $86.1 \pm 0.90$ \\
SOC/TN & $10.1 \pm 0.25$ \\
\hline
\end{tabular}

The values are mean \pm standard error.

SOC: Soil organic C; TN: total N.

Machinery, Shanghai, China) 2-3 d before rice or rape sowing. However, in case of CTS and NTS, rice-rape crops residues were taken out from preceding crops were chopped 5-8 $\mathrm{cm}$ length and retained back into fields. In CTS plots, chopped rice-rape residues were incorporated in field through ploughing to $20 \mathrm{~cm}$ depth. For NTS, chopped residues were retained or left on the soil surface; following this, the rice was transplanted or the rape was sowed with a no-tillage planter. In the straw returning plots, $4200 \mathrm{~kg} \mathrm{ha}^{-1}$ straw for both rice and rape was returned back into the soil. After the rice was harvested, air-dried residues of rice were returned to the soil $3 \mathrm{wk}$ before rape was seeded and rape residues were returned to soil $3 \mathrm{wk}$ before rice was planted. Straw was equally incorporated in the field to reduce variation between treatments.

Chemical inorganic fertilizers were applied during rice-rape growing seasons. Fertilization was broadcasted before sowing or planting, with rape receiving basal doses of $\mathrm{N}, \mathrm{P}$, and $\mathrm{K}$ at $210 \mathrm{~kg} \mathrm{~N} \mathrm{ha}^{-1}, 75 \mathrm{~kg} \mathrm{P}_{2} \mathrm{O}_{5} \mathrm{ha}^{-1}$, and 150 $\mathrm{kg} \mathrm{K}_{2} \mathrm{O} \mathrm{ha}^{-1}$, respectively, and rice receiving at $150 \mathrm{~kg} \mathrm{~N} \mathrm{ha}^{-1}, 60 \mathrm{~kg} \mathrm{P}_{2} \mathrm{O}_{5} \mathrm{ha}^{-1}$ and $135 \mathrm{~K}_{2} \mathrm{O}_{5}$ ha $^{-1}$, respectively. During rice crop growing seasons, $\mathrm{N}$ fertilizer was applied as urea fertilizer (containing $\mathrm{N} 46 \%$ ) in three splits: 50\% $\mathrm{N}$ (as 46\% urea) was used as basal N, $30 \%$ at the tillering stage and $20 \%$ at the earing stage. In rape seasons, $60 \%$ was applied a basal dose, $20 \%$ was applied in wintering stage, and $20 \%$ applied at initiation of stem elongation stage. All P fertilizer (as single superphosphate, $12 \% \mathrm{P}_{2} \mathrm{O}_{5}$ ) and $\mathrm{K}$ (as potassium chloride, $60 \% \mathrm{~K}_{2} \mathrm{O}$ ) was applied as a base dose in each cropping season after throwing rice seedlings or sowing rape.

Rice (Wu you308) and rape (Hua youza62) varieties were cultivated in this study; they were selected on the base of their local importance and extensive adaptability in Hubei province of central China. The nursery of rice crop was raised on a fertile seedbed and was transplanted to the field after 30 days of seedling emergence for each growing season. Rape was directly seeded at $4.5 \mathrm{~kg} \mathrm{ha}^{-1}$ in November of each year and harvested manually in June. All other agronomic management practices such as, irrigation, weed control, disease control and herbicide application were performed using conventional practices of Hubei province. In rice growing seasons, weeds were controlled by local practices of herbicide as spraying $36 \%$ glyphosate at $3 \mathrm{~L} \mathrm{ha}^{-1}$, manual weeding was also done in rape crops to keep the plots weeds free. 


\section{Soil sampling and analytical methods}

The soil samples were collected on May of each year after the rape harvest from each plot in the experimental field at depths of 0-20 and 20-40 cm. A total of 24 samples (four treatments $\times$ two depths $\times$ three replicates) were collected in 2013-2015 each year. Later, the soil samples were delivered to a laboratory, after carefully removing fine roots, residues and unwanted surface organic material. The portion of the soil samples were passed again through a $0.15 \mathrm{~mm}$ sieve to determine the SOC concentration. To determine the aggregate size distribution, undisturbed soil cores were collected from the 0-20 and 20-40 cm depths, with separate samples taken repeatedly from each depth. The texture of the soil was determined by the pipette method; soil $\mathrm{pH}$ was measured at a soil:water extract ratio (1:2.5); SOC concentration was measured by the potassium dichromate $\left(\mathrm{K}_{2} \mathrm{Cr}_{2} \mathrm{O}_{7}\right)$ wet oxidation method; total $\mathrm{N}$ was measured using the Kjeldhal digestion method. Total $\mathrm{P}$ was measured after perchloric and sulfuric acid digestion method. Available $\mathrm{P}$ was measured in extraction solution $0.5 \mathrm{M} \mathrm{NaHCO}_{3}$, adjusted at $\mathrm{pH} 8.5$ as suggested by Olsen and Sommers (1982). Total and available $\mathrm{K}$ was measured following Kundsen et al. (1982).

The proportions of water-stable aggregates were determined by placing $50 \mathrm{~g}$ air-dried soil samples on the top of different size sieves $(>5,5-2,2-1,1.0-0.5,0.25-0.5$, and $<0.25 \mathrm{~mm})$. The soil samples on a set of sieves were immersed in water, and agitated up and down within $10 \mathrm{~cm}$ at a rate of 35 cycles per minute for $10 \mathrm{~min}$ (Kemper and Rosenau, 1986). These samples were transferred to a container, oven-dried at $60{ }^{\circ} \mathrm{C}$, and then weighed. Mean weight diameter (MWD) and geometric mean diameter (GMD), two indicators of aggregate stability, were calculated on the basis of aggregate size distribution of the soil samples (Kemper and Rosenau, 1986) by using the following equations:

$$
\mathrm{MWD}=\sum_{i=1}^{n} \mathrm{XW}_{\mathrm{i}}
$$

where $X$ denotes the mean of the diameter of the aggregates remaining on the sieve, and $W_{i}$ denotes the ratio of the persistent aggregate weight on the sieve to the total sample weight, and $n$ denotes the total number of sieves used for separation.

$$
\mathrm{GMD}=\exp \left(\frac{\sum_{i=1}^{n} \mathrm{WilogXi}}{\sum_{i=1}^{n} \mathrm{Wi}}\right)
$$

In the above equation, $W_{i}$ indicates the total dry weight of the aggregates, $n$ indicates the number of sieves, and $X_{i}$ indicates the mean diameter of aggregates over each size of sieve.

Fractal dimension (FD) was developed to determine stability of the soil aggregates with mass distribution of particles instead of size distribution of particles due fractal features of the soil (Tyler and Wheatcraft, 1989). The lesser the fractal dimension value, the greater the soil stability to resist mechanical or water dispersion. The fractal formula was defined as follows:

$$
\frac{W\left(r<\bar{d}_{\mathrm{i}}\right) M(X)}{\mathrm{W}_{\mathrm{T}}}=\left[\frac{\bar{d}_{\mathrm{i}}}{d_{\max }}\right]^{3-D}
$$

where, $r$ is the soil particle size, $d_{i}$ is the particle size of grade $i$ in the particle size grading, $d_{\max }$ is the average diameter of the soil particles; $W(r<d i)$ is the weight of the soil particles with a diameter less than $d_{i}, W_{T}$ is the weight of all soil particles and $D$ is the fractal dimension value. We took the logarithmic transformation on both sides of equation, and fractal dimensions $D$ value of all soil samples was obtained on the base of the slopes of the logarithmic curves that fit the data.

\section{Statistical analysis}

The statistical analysis was carried out by the SPSS (Statistical Package for the Social Sciences; IBM, Armonk, New York, USA) package. The difference in SOC, water stable aggregate size distribution, MWD, GMD, and FD as affected by tillage practices, straw returning, year and their interaction were assessed by using a two-way ANOVA. Treatments were compared on the basis of significant difference with least significance difference (LSD, $\mathrm{P}<0.05$ ). The associations among SOC, MWD, GMD, FD, and water stable aggregates were observed through Pearson correlation analysis. 


\section{RESULTS AND DISCUSSION}

\section{Soil organic C}

Tillage and straw returning treatments had a significantly higher SOC content than the other treatments in both soil depths (Figure 2). The greater SOC content in the $0-20 \mathrm{~cm}$ was observed under straw retuning plots NTS and CTS treatments throughout $3 \mathrm{yr}$ (2013-2015). In year wise comparison, NTS treatment had comparatively higher results as compared to CT, which increased from 15.7 to $18.8 \mathrm{~g} \mathrm{~kg}^{-1}$ (2013), 15.8 to $19.0 \mathrm{~g} \mathrm{~kg}^{-1}$ (2014), and 16.2 to $20.2 \mathrm{~g} \mathrm{~kg}^{-1}$ (2015) in 0-20 cm depth (Figure 2). Similar higher changes were also found in NT or NTS treatment in other studies (Angers and Eriksen-Hamel, 2008; Zhang et al., 2014). However, a variable trend was observed between the treatments in 20-40 $\mathrm{cm}$ depth, which were changed from 3.2 to $5.0 \mathrm{~g} \mathrm{~kg}^{-1}$ (2013), 3.9 to $5.2 \mathrm{~g} \mathrm{~kg}^{-1}$ (2014), and 4.8 to $6.1 \mathrm{~g} \mathrm{~kg}^{-1}$ (Figure 2). The significant interactive effect of the straw returning and tillage treatments on the SOC content was obtained at the $0-20 \mathrm{~cm}$ for the whole soil profile $(0-40 \mathrm{~cm})$, during the $3 \mathrm{yr}$ the trend was NTS $>$ CTS $>$ CT $>$ NT. The average SOC content indicates that NTS significantly increased the SOC content the 0-20 cm depth in relative to the other three treatments. Similarly, Rajan et al. (2012) and Xin et al. (2015) reported that main differences occur between NT and CT in the upper top layer of the soil.

The present study divulged that NTS and CTS treatments significantly increase the SOC content of the 0-20 cm depth in comparison with CT treatment. Similar to this study, Six et al. (2002) discussed that the response of SOC under NT treatment was increase after 6-8 yr of the study at 0-30 cm. Another researcher (Singh et al., 2016) discussed that crop establishment techniques and residue management significantly increased SOC after $5 \mathrm{yr}$ at 0-15 and 15-30 cm depths. Higher SOC content under straw returning plots NTS and CTS treatment in the surface layer may be associated higher inputs of straw residue, which resulting the high retention of SOC content in surface soil (Angers and Eriksen-Hamel, 2008; Gathala et al., 2015). The higher SOC content may also be because of the interactive effect of tillage and straw returning, due to higher conversion efficiency of straw residue C into SOC (Rajan et al., 2012; Al-Kaisi et al., 2014; Gathala et al., 2015). The diverse studies also suggest that tillage influences on SOC can be depended on regional factors, i.e., soil type, residue management, crop rotation, region, type of clay and land management practices (Rabbi et al., 2015).

\section{Aggregate size distribution}

Aggregate size distribution percentages were affected by tillage and straw returning practices in both soil depths (Tables 2 and 3). The percentage of the $>5,2-5,1-2,0.5-1.0 \mathrm{~mm}$ under straw returning plots NTS and CTS were significantly or nonsignificantly higher than those of other treatments at 0-20 and 20-40 cm soil depth of 2013-2015. Meanwhile, the contribution percentages of 0.25-0.5 and $<0.25 \mathrm{~mm}$ were inconstant between the treatments from 2013-2015 for both $0-20$ and $20-40 \mathrm{~cm}$ depth. The higher percentage of $>5 \mathrm{~mm}$ aggregates $(57.90 \%)$ was recorded under NTS in

Figure 2. Soil organic carbon content in different treatments.
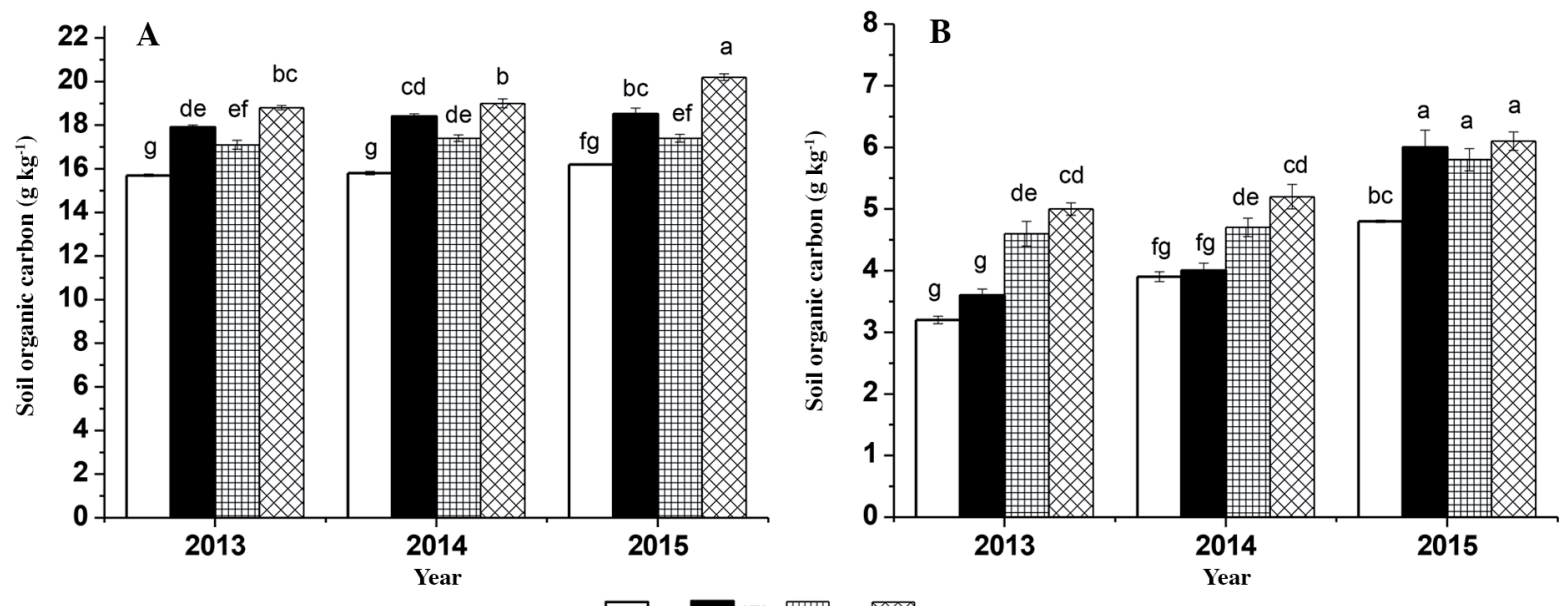

A: $0-20 \mathrm{~cm}$ and B: $20-40 \mathrm{~cm}$.

CT: Conventional tillage, CTS: conventional tillage with straw returning, NT: no-tillage, NTS: no-tillage with straw returning. Bars with different lower-case letters indicate significant differences at $\mathrm{p}<0.05$. 
Table 2. Water stable aggregate size distribution $(\%)$ at $0-20 \mathrm{~cm}$ soil depth under different tillage and straw returning treatments.

\begin{tabular}{|c|c|c|c|c|c|c|c|}
\hline \multirow[b]{2}{*}{ Year } & \multirow[b]{2}{*}{ Treatments } & \multicolumn{6}{|c|}{ Soil aggregate size distribution } \\
\hline & & $>5 \mathrm{~mm}$ & $2-5 \mathrm{~mm}$ & $1-2 \mathrm{~mm}$ & $0.5-1.0 \mathrm{~mm}$ & $0.25-0.5 \mathrm{~mm}$ & $<0.25 \mathrm{~mm}$ \\
\hline \multirow[t]{4}{*}{2013} & $\mathrm{CT}$ & $10.03 \mathrm{~h}$ & $4.05 \mathrm{f}$ & $4.80 \mathrm{~cd}$ & $9.05 \mathrm{cde}$ & $11.41 \mathrm{cde}$ & $47.00 \mathrm{~b}$ \\
\hline & CTS & $16.12 \mathrm{~g}$ & 5.31def & $5.95 \mathrm{a}$ & $10.69 \mathrm{~cd}$ & $11.74 \mathrm{ab}$ & $55.63 \mathrm{a}$ \\
\hline & NT & $16.72 \mathrm{~g}$ & $4.50 \mathrm{f}$ & $5.02 \mathrm{bcd}$ & $10.28 \mathrm{cde}$ & $10.81 \mathrm{def}$ & $51.59 \mathrm{~b}$ \\
\hline & NTS & $19.01 \mathrm{dfg}$ & $6.08 \mathrm{bc}$ & $5.58 \mathrm{abc}$ & $10.42 \mathrm{~cd}$ & $13.31 \mathrm{~cd}$ & $49.40 \mathrm{~b}$ \\
\hline \multirow[t]{4}{*}{2014} & $\mathrm{CT}$ & $20.64 f$ & $6.76 b c$ & $5.37 \mathrm{abc}$ & $10.69 \mathrm{~cd}$ & $8.72 \mathrm{~g}$ & $39.23 \mathrm{~d}$ \\
\hline & CTS & $32.09 \mathrm{e}$ & 4.77ef & $5.84 \mathrm{ab}$ & $11.70 \mathrm{c}$ & 11.50def & $43.08 \mathrm{c}$ \\
\hline & NT & $41.03 \mathrm{~d}$ & $4.55 \mathrm{f}$ & 4.46de & $9.85 \mathrm{de}$ & $13.13 \mathrm{~cd}$ & $30.41 \mathrm{f}$ \\
\hline & NTS & $52.05 \mathrm{~b}$ & $5.84 \mathrm{cde}$ & $4.06 \mathrm{e}$ & $8.63 \mathrm{e}$ & 11.30def & $35.59 \mathrm{e}$ \\
\hline \multirow[t]{9}{*}{2015} & $\mathrm{CT}$ & $38.57 \mathrm{~d}$ & $5.44 \mathrm{a}$ & $4.89 \mathrm{~cd}$ & $10.66 \mathrm{~cd}$ & $11.97 \mathrm{def}$ & $25.11 \mathrm{~g}$ \\
\hline & CTS & $21.91 \mathrm{f}$ & $6.22 \mathrm{a}$ & $5.02 \mathrm{~cd}$ & $12.90 \mathrm{~b}$ & $12.81 \mathrm{cde}$ & $27.39 \mathrm{~g}$ \\
\hline & NT & $57.90 \mathrm{a}$ & $7.88 \mathrm{a}$ & $5.36 \mathrm{ab}$ & $14.01 \mathrm{ab}$ & $16.34 \mathrm{a}$ & $34.39 \mathrm{e}$ \\
\hline & NTS & $46.93 c$ & $5.92 \mathrm{a}$ & $6.08 \mathrm{a}$ & $14.89 \mathrm{a}$ & $14.54 \mathrm{ab}$ & $20.88 \mathrm{~h}$ \\
\hline & ANOVA & & & & & & \\
\hline & $\mathrm{T}$ & $* *$ & $* *$ & NS & NS & $* *$ & $* *$ \\
\hline & $\mathrm{S}$ & $* *$ & $* *$ & NS & $*$ & NS & $* *$ \\
\hline & $\mathrm{Y}$ & $* *$ & $* *$ & * & $*$ & $* *$ & $* *$ \\
\hline & $\mathrm{T} \times \mathrm{S} \times \mathrm{Y}$ & $* *$ & $* *$ & NS & NS & $* *$ & $*$ \\
\hline
\end{tabular}

CT: Conventional tillage, CTS: conventional tillage with straw returning, NT: no-tillage, NTS: no-tillage with straw returning.

Different lower-case letter in a line denotes significant difference at the $5 \%$ level.

Values followed by the same lower-case letter are nonsignificantly different according to Duncan's multiple range test ( $\mathrm{p}>0.05$ ) different years of the treatments.

T: Tillage, S: straw returning, Y: year, NS: nonsignificant.

$*$,**Significant at the 0.05 and 0.01 probability levels, respectively.

Table 3. Water stable aggregate size distribution $(\%)$ at $20-40 \mathrm{~cm}$ soil depth of under different tillage and straw returning treatments.

\begin{tabular}{|c|c|c|c|c|c|c|c|}
\hline \multirow[b]{2}{*}{ Year } & \multirow[b]{2}{*}{ Treatments } & \multicolumn{6}{|c|}{ Soil aggregates size $(\mathrm{mm})$} \\
\hline & & $>5 \mathrm{~mm}$ & $2-5 \mathrm{~mm}$ & $1-2 \mathrm{~mm}$ & $0.5-1.0 \mathrm{~mm}$ & $0.25-0.5 \mathrm{~mm}$ & $<0.25 \mathrm{~mm}$ \\
\hline \multirow[t]{4}{*}{2013} & $\mathrm{CT}$ & $8.33 c$ & $4.05 \mathrm{ab}$ & $3.33 \mathrm{efg}$ & 5.69 & $11.26 \mathrm{de}$ & $45.62 f$ \\
\hline & CTS & $15.21 \mathrm{~b}$ & 3.39abc & $2.92 \mathrm{~g}$ & $8.82 \mathrm{c}$ & $11.32 \mathrm{de}$ & $54.26 \mathrm{e}$ \\
\hline & NT & $7.83 \mathrm{c}$ & $4.37 \mathrm{a}$ & $3.07 \mathrm{fg}$ & $6.13 \mathrm{ef}$ & $8.34 \mathrm{f}$ & $44.39 f$ \\
\hline & NTS & $18.14 \mathrm{a}$ & $3.44 \mathrm{abc}$ & $2.79 \mathrm{~g}$ & $6.52 \mathrm{ef}$ & $10.68 \mathrm{de}$ & $51.64 \mathrm{e}$ \\
\hline \multirow[t]{4}{*}{2014} & $\mathrm{CT}$ & $2.16 f g$ & $3.31 \mathrm{bcd}$ & $4.04 \mathrm{bcde}$ & 7.20de & $9.82 \mathrm{ef}$ & $67.65 \mathrm{~cd}$ \\
\hline & CTS & $2.14 \mathrm{fg}$ & $2.37 \mathrm{def}$ & $3.68 \mathrm{cdef}$ & $10.76 b$ & $14.88 \mathrm{~b}$ & $70.17 \mathrm{c}$ \\
\hline & NT & $3.04 \mathrm{ef}$ & $2.28 \mathrm{ef}$ & 3.40defg & $6.44 \mathrm{ef}$ & $10.46 \mathrm{ef}$ & $70.75 \mathrm{bc}$ \\
\hline & NTS & $4.44 \mathrm{e}$ & $3.33 \mathrm{bcd}$ & $4.10 \mathrm{bcd}$ & $8.09 \mathrm{~cd}$ & $10.40 \mathrm{de}$ & $64.92 d$ \\
\hline \multirow[t]{9}{*}{2015} & $\mathrm{CT}$ & $2.88 \mathrm{ef}$ & $2.70 \mathrm{cdef}$ & $4.26 \mathrm{abc}$ & $9.45 b c$ & $12.92 \mathrm{~cd}$ & $70.22 c$ \\
\hline & CTS & $3.10 \mathrm{ef}$ & $3.20 \mathrm{bcde}$ & $4.82 \mathrm{a}$ & $13.92 \mathrm{a}$ & $14.81 \mathrm{~b}$ & $78.46 a$ \\
\hline & NT & $1.94 \mathrm{ef}$ & $1.80 \mathrm{f}$ & $4.57 \mathrm{ab}$ & $12.64 \mathrm{a}$ & $12.94 \mathrm{~cd}$ & $67.10 \mathrm{~cd}$ \\
\hline & NTS & $3.82 \mathrm{e}$ & $2.59 \mathrm{cdef}$ & $3.99 \mathrm{bcde}$ & $12.66 \mathrm{a}$ & $17.89 \mathrm{a}$ & $74.67 \mathrm{ab}$ \\
\hline & ANOVA & & & & & & \\
\hline & $\mathrm{T}$ & NS & NS & NS & $*$ & $* *$ & $*$ \\
\hline & $\mathrm{S}$ & $* *$ & NS & NS & $*$ & $* *$ & $* *$ \\
\hline & $\mathrm{Y}$ & $* *$ & $*$ & $*$ & $* *$ & $* *$ & $* *$ \\
\hline & $\mathrm{T} \times \mathrm{S} \times \mathrm{Y}$ & $* *$ & NS & $*$ & $* *$ & $* *$ & $*$ \\
\hline
\end{tabular}

CT: Conventional tillage, CTS: conventional tillage with straw returning, NT: no-tillage, NTS: no-tillage with straw returning.

Different lower-case letter in a line denotes significant difference at the $5 \%$ level.

Values followed by the same lower-case letter are nonsignificantly different according to Duncan's multiple range test ( $\mathrm{p}>0.05$ ) between the different years of the treatments.

T: Tillage, S: straw returning, Y: year, NS: non-significant.

$*$, **Significant at the 0.05 and 0.01 probability levels, respectively.

2015 at 0-20 cm depth. In 20-40 $\mathrm{cm}$ depth, the higher percentage of $<0.25 \mathrm{~mm}$ soil aggregates was $78.4 \%$ under CTS treatment in 2013. Likewise to our results, Kushwaha et al. (2001) observed that residue retention significantly increased the proportion of $>4.75 \mathrm{~mm}$ in minimum tillage and residue-retained treatments. The interactive effect of tillage and straw returning were significant for all size of aggregates except (1-2 and 0.5-1.0 mm) at 0-20 cm and except for 2-5 
$\mathrm{mm}$ at $20-40 \mathrm{~cm}$. With an increase in the duration of these treatments, CTS, NT, and NTS practices in 2015 significantly enhanced the percentage of macroaggregates $(>5,2-5,1-2,0.5-1.0,0.25-0.5 \mathrm{~mm})$, but decreased the percentage of the microaggregates $(<0.25)$ at $0-20 \mathrm{~cm}$ depth. However, reverse trend was observed at $20-40 \mathrm{~cm}$ depth, increased the percentage of microaggregates $(<0.25 \mathrm{~mm})$, but decreased the percentage of macroaggregates $(>5,2-5,1-2,0.5-1.0$, $0.25-0.5 \mathrm{~mm})$. Alike to these findings that macro-aggregate $(>0.25 \mathrm{~mm})$ proportion were significantly changed by NTS at upper soil layer (0-20 cm) but decreased at lower depth (Liu et al., 2014; Xin et al., 2015). In this study, NTS treatment significantly increased macroaggregates $(>0.25 \mathrm{~mm})$ at the $0-20 \mathrm{~cm}$ depth and increased microaggregates $(<0.25 \mathrm{~mm})$ at $20-40 \mathrm{~cm}$ depth in comparison with CT treatment. It was mainly because soil microaggregates $(<0.25 \mathrm{~mm})$ consist of small particles, coated with fine organic and inorganic materials. However, macroaggregates $(>0.25 \mathrm{~mm})$ are result of gathering of small particles (Gwenzi et al., 2009). The stability of these soil aggregates affected due to the tillage and residue management practices (Six et al., 2000), macroaggregates were of low stable and persistence because they are weekly cemented by organic residues (Six et al., 2000; Sandoval et al., 2007), such type of soil aggregates could readily disintegrate into smaller units under wet sieving. When soil aggregates were affected due mechanical disturbance of soil (e.g., under CT), the SOC interacted with aggregates released and aggregate size decreased. This was reported by Mikha and Rice (2004) that CT considerably decreased macroaggregates $(>2.0 \mathrm{~mm}$ and $0.25-2 \mathrm{~mm})$ and with a coincident increase in microaggregates $(<0.25 \mathrm{~mm})$ after $10 \mathrm{yr}$ in a silt loam soil. Sandoval et al. (2007) also observed that there was a higher contents of macro-aggregates $(>0.5 \mathrm{~mm})$ than in micro-aggregates $(<0.5 \mathrm{~mm})$ in south-central Chile.

\section{Mean weight diameter and geometric mean diameter of soil aggregates}

Mean weight diameter (MWD) and geometric mean diameter (GMD) of soil aggregates significantly varied with tillage, straw returning, year and their interaction (Figures 3 and 4). The average values of MWD and GMD in 2015 ranged from 3.25 to 3.53 and 1.0 to 1.3 , respectively, as compared to 2013, ranged from 1.61 to 1.92 and 0.74 to 0.81 , respectively. MWD and GMD under straw returning plots NTS and CTS were higher than those of other treatments with significant difference in 2015 than 2013. These results are same with another study that MWD was significantly affected by straw returning and no-tillage systems in the top 0-30 cm (Gwenzi et al., 2009). In agreement to our results, Kahlon et al. (2013) and Chen et al. (2014) reported that crop straw addition improved the aggregate stability of soil. The trend in depth regarding MWD decreasing from top to bottom of the soil with higher values under NTS treatments. Higher values under NTS than their counterpart CT treatments was due to less soil disturbance and residue retention. In 20-40 cm depth, MWD and GMD values in 2015 ranged from 0.70 to 0.98 and 0.58 to 0.72 , respectively in comparison to 2013 , which ranged from 0.34 to 0.47 and 0.47 to 0.53 , respectively. The overall MWD and GMD values in the treatments followed the order of NTS $>$ CTS $>$ NT $>$ CT at the $0-20 \mathrm{~cm}$ depth, and NTS $>$ CTS $>$ NT $=$ CT at the 20-40 cm depth.

Figure 3. Mean weight diameter content of soil aggregates in different treatments.


A: $0-20 \mathrm{~cm} . \mathrm{B}: 20-40 \mathrm{~cm}$

CT: Conventional tillage, CTS: conventional tillage with straw returning, NT: no-tillage, NTS: no-tillage with straw returning. Bars with different lower-case letters indicate significant differences at $\mathrm{p}<0.05$. 
Figure 4. The geometric mean diameter content of soil aggregates in different treatments.

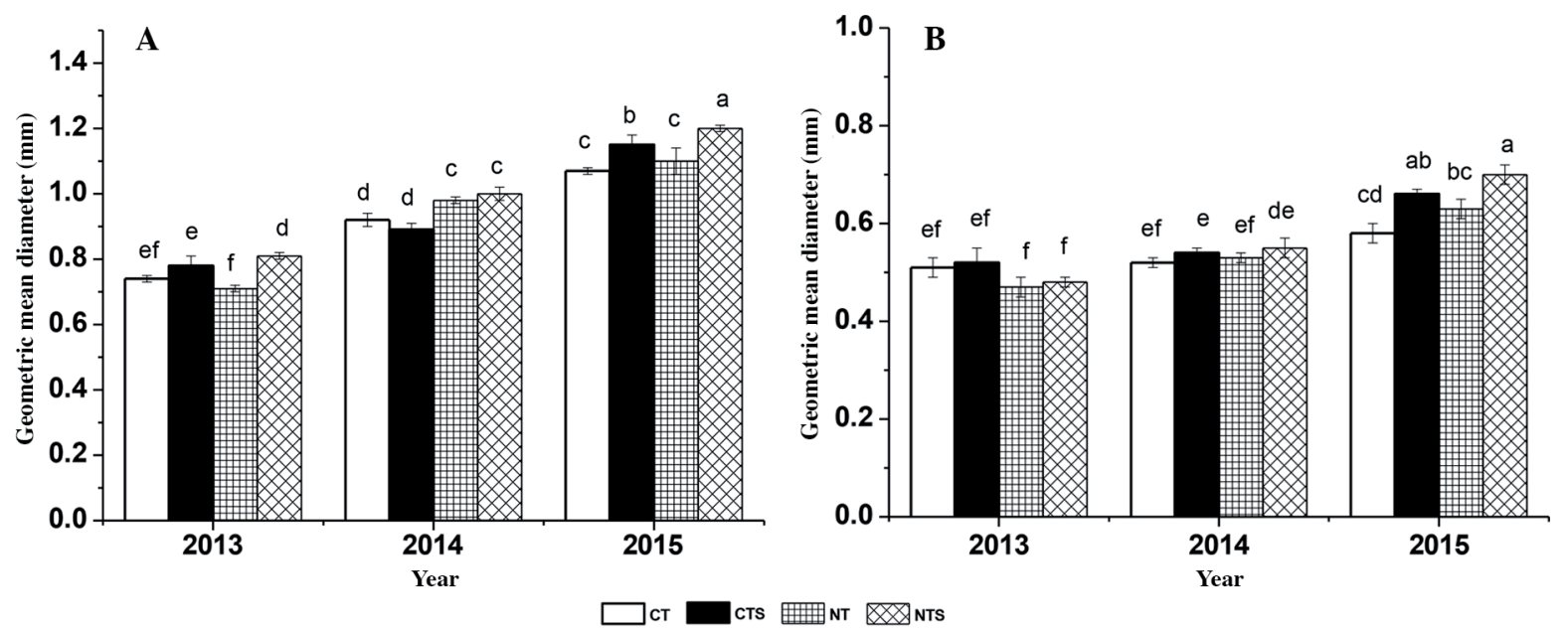

A: $0-20 \mathrm{~cm} . \mathrm{B}: 20-40 \mathrm{~cm}$.

CT: Conventional tillage, CTS: conventional tillage with straw returning, NT: no-tillage, NTS: no-tillage with straw returning.

Bars with different lower-case letters indicate significant differences at $\mathrm{p}<0.05$.

In present study, tillage and straw returning plots NTS and CTS treatments significantly increased MWD and GMD values of soil aggregates in both soil depths, but was more obvious at 0-20 cm depth. Soil aggregate stability always determined in relation to MWD and GMD, indicate the soil capability to resist degradation (Kemper and Rosenau, 1986). The effect of tillage on MWD and GMD was linked with residue placement, these finding consisted with others organic residues enhance MWD of soil aggregates (Dameni et al., 2010). Karami et al. (2012) reported that straw application improved the aggregate stability and other soil properties. This is coincident with these results that GMD values with the straw incorporation treatments improved significantly throughout under 3 yr study (Zhang et al., 2014). Improvement in stability of soil aggregates with NT may endorsed obviously near to the surface soil $(<10 \mathrm{~cm})$ (Stone and Schlegel, 2010; Kahlon et al., 2013). In this study, we found distinct difference in GMD at surface soil, the distinct difference could be related with the continuous organic matter placement in the surface soil, the high stable soils always characterized due high addition of soil organic matter (Sandoval et al., 2007; Paul et al., 2013). These present study results were comparable with others studies (Zhou et al., 2007; Zhang et al., 2014), probably associated with change in aggregate size distribution during tillage processes and suggesting that increases in soil organic matter could also increase soil aggregation and stability in the study soil (Kibet et al., 2016).

\section{Fractal dimensions}

Tillage and straw returning treatments had a nonsignificant effect on fractal dimensions of the soil aggregates in both soil depths (Figure 5). The fractal dimension (FD) value varied from 2.81 to 2.99 from 2013 to 2015 at $0-20 \mathrm{~cm}$ depth. The FD value also increased with increasing soil depth. In 2013-2015, NT and NTS treatments had comparatively higher FD values which varied from 2.88 to 2.99 at the $20-40 \mathrm{~cm}$ depth, but the difference was nonsignificant. Overall, a larger FD value was noted under NTS treatment than the other treatments at both depths during the $3 \mathrm{yr}$.

In this present study, the fractal dimension D of soil aggregates nonsignificantly increased in both depths under NTS treatments. The distinct difference in fractal dimensions D of water stable aggregates was obvious in the surface soil. Similarly also reported in some other studies (Zhou et al., 2007; Zhang et al., 2014). The improvement in the fractal dimensions may have been accelerated by the returned residue retention, which increased aggregate stability, SOC (Gwenzi et al., 2009), and significantly increased aggregate size distribution (Six et al., 2000). Fractal dimensions D can be more strongly affected by the changes in land management and residue management practices in agro-ecosystem. In this study, soil was characterized by the increased values of fractal dimensions in NTS, in comparison to CT treatments. Previous studies also suggested that organic residues treatments usually had higher fractal dimensions that other cropland system (Tripathi et al., 2012; Zhang et al., 2014). 
Figure 5. Fractal dimensions of different treatments.

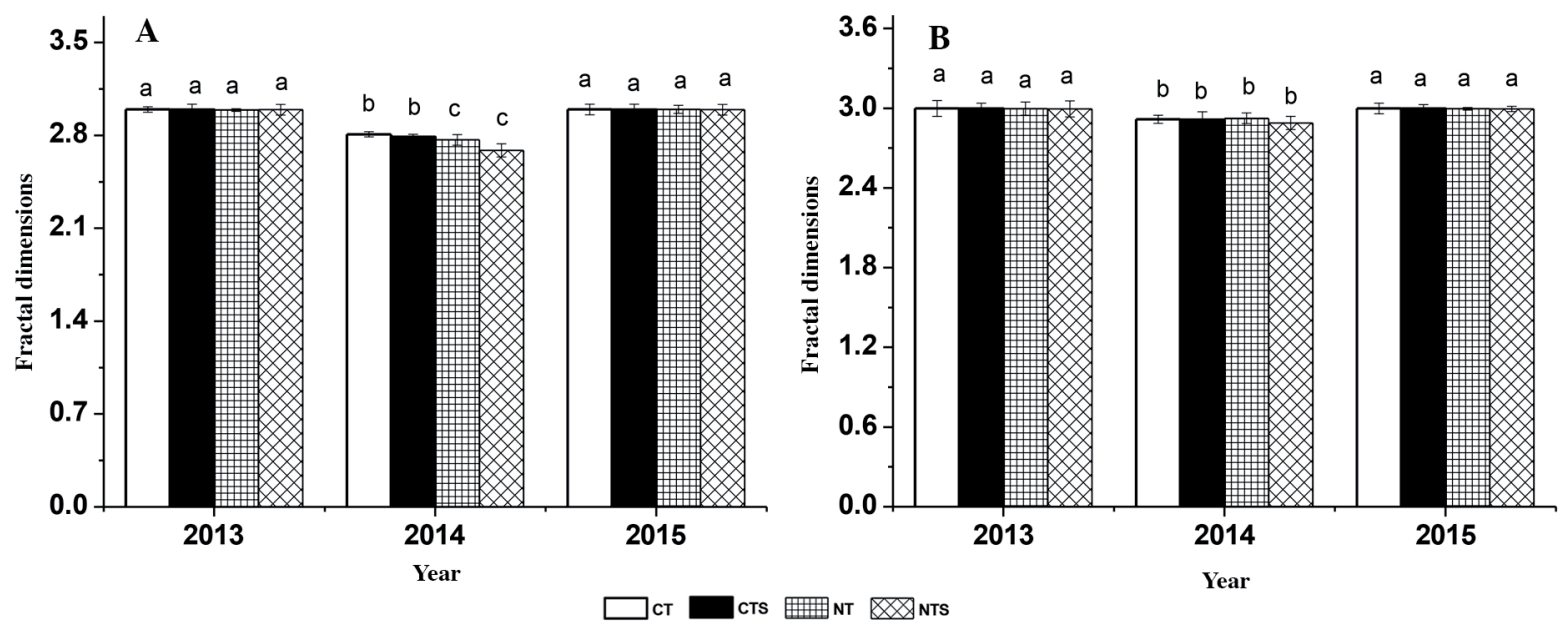

A: $0-20 \mathrm{~cm} . \mathrm{B}: 20-40 \mathrm{~cm}$.

CT: Conventional tillage, CTS: conventional tillage with straw returning, NT: no-tillage, NTS: no-tillage with straw returning.

Bars with different lower-case letters indicate significant differences at $\mathrm{p}<0.05$.

\section{Relationship of SOC with different soil aggregates}

The correlation analysis revealed that SOC was positively or negatively $(\mathrm{p}<0.05)$ correlated with $>5,2-5,1-2,0.25-0.5$, $<0.25 \mathrm{~mm}, \mathrm{MWD}$, GMD, and FD except 0.5-1.0 mm soil aggregate size (Table 4). The correlation coefficients varied from -28 to 0.97 . Compared to others, macroaggregates $>5 \mathrm{~mm}$ had positively higher correlation coefficient with SOC $0.80^{* *}$, MWD $0.97^{* *}$ and MWD $0.97^{* *}$. Correlation analysis further supported that the content of SOC had a distinct significant relationship with $>5 \mathrm{~mm}$ macroaggregates.

Gwenzi et al. (2009) pointed out that, when both SOC and aggregation were generally low, the correlation represented the lower extreme of the relationship between SOC and soil aggregates. Biswas et al. (2009) observed increased (linear) content of SOC for larger size soil aggregates, which similar to our results. However, most of the SOC in soils is concomitant with the fine soil fraction and the dominant mechanism is chemical protection of soil structure (Six et al., 2000). Macroaggregates $(>0.25 \mathrm{~mm})$ and soil aggregates stability was associated to loosely and tightly combined SOC content in the soil (Blanco-Canqui et al., 2011). Xin et al. (2015) also observed that soil SOC content was positively correlated with MWD $\left(r^{2}=0.94\right)$ and GMD $\left(r^{2}=0.92\right)$.

Table 4. Pearson correlation coefficient (r-value) and significance among soil organic carbon, mean weight diameter, geometric mean diameter, fractal dimensions and different soil aggregates $(n=72)$.

\begin{tabular}{|c|c|c|c|c|c|c|c|c|c|}
\hline & SOC & MWD & GMD & FD & $>5 \mathrm{~mm}$ & $2-5 \mathrm{~mm}$ & $1-2 \mathrm{~mm}$ & $0.5-1.0 \mathrm{~mm}$ & $0.5-0.25 \mathrm{~mm}$ \\
\hline MWD & $0.82 * *$ & 1.00 & & & & & & & \\
\hline GMD & $0.78 * *$ & $0.98 * *$ & 1.00 & & & & & & \\
\hline FD & $-0.28 *$ & $-0.39 * *$ & $-0.34 * *$ & 1.00 & & & & & \\
\hline$>5 \mathrm{~mm}$ & $0.80 * *$ & $0.97 * *$ & $0.97 * *$ & $-0.36^{* *}$ & 1.00 & & & & \\
\hline $2-5 \mathrm{~mm}$ & $0.72 * *$ & $0.56^{* *}$ & $0.51 * *$ & $-0.07 \mathrm{~ns}$ & $0.50 * *$ & 1.00 & & & \\
\hline $1-2 \mathrm{~mm}$ & $0.75^{* *}$ & $0.57 * *$ & $0.55^{* *}$ & $-0.06 \mathrm{~ns}$ & $0.50 * *$ & $0.63 * *$ & 1.00 & & \\
\hline $0.5-1.0 \mathrm{~mm}$ & $-0.18 \mathrm{~ns}$ & $-0.28 *$ & $-0.25 *$ & $0.22 *$ & $-0.26^{*}$ & $-0.02 \mathrm{~ns}$ & $-0.02 \mathrm{~ns}$ & 1.00 & \\
\hline $0.5-0.25 \mathrm{~mm}$ & $0.47 * *$ & $0.48^{* *}$ & $0.50 * *$ & $0.13 \mathrm{~ns}$ & $0.44 * *$ & $0.45^{* *}$ & $0.70 * *$ & $0.40^{* *}$ & 1.00 \\
\hline$<0.25 \mathrm{~mm}$ & $-0.78 * *$ & $-0.92 * *$ & $-0.92 * *$ & $0.17 \mathrm{~ns}$ & $-0.90 * *$ & $-0.62 * *$ & $-0.66 * *$ & $0.07 \mathrm{~ns}$ & $-0.68 * *$ \\
\hline
\end{tabular}

ns: Nonsignificant. *,** Significant correlation at 0.05 and 0.01 probability levels, respectively.

SOC: Soil organic C, MWD: mean weight diameter, GMD: geometric mean diameter, FD: fractal dimensions. 


\section{CONCLUSIONS}

No-tillage with straw returning (NTS) had significantly higher soil organic C (SOC) content, soil macroaggregates, mean weight diameter (MWD), geometric mean diameter (GMD) and fractal dimensions (FD) values in 0-20 cm depth. In 20-40 cm depth, the soil micro-aggregates were higher under conventional tillage with straw returning (CTS) treatment. Combined use of no-tillage (NT) and straw returning significantly increased the SOC content and contribution of macroaggregates and microaggregates at $0-40 \mathrm{~cm}$ depth. Interactive effects of NT and straw returning were significantly noticeable in 0-20 cm soil depth. SOC was significantly correlated with macroaggregates, microaggregates, MWD, GMD in 0-40 cm depth. The long-term maintenance of NT and straw returning over time enhanced the percentage of large macroaggregates and SOC content in rice-rape rotation. Therefore, this study concluded that integrative application of NTS is suitable option for improving SOC content and soil quality in rice-rape rotation system.

\section{ACKNOWLEDGEMENTS}

This research was supported by the Special Fund for Agro-scientific Research in the Public Interest (Grant No. 201503123), the National Natural Science Foundation of People's Republic of China (Grant No. 41271252).

\section{REFERENCES}

Al-Kaisi, M.M., Douelle, A., and Kwaw-Mensah, D. 2014. Soil micro-aggregate and macro-aggregate decay over time and soil carbon change as influenced by different tillage systems. Journal of Soil Water Conservation 69:574-580.

Angers, D.A., and Eriksen-Hamel, N.S. 2008. Full-inversion tillage and organic carbon distribution in soil profiles: a metaanalysis. Soil Science Society of America Journal 72:1370-1374.

Bhattacharyya, R., Tuti, M.D., Bisht, J.K., Bhatt, J.C., and Gupta, H.S. 2012. Conservation tillage and fertilization impacts on soil aggregation and carbon pools in the Indian Himalayas under an irrigated rice-wheat rotation. Soil Science 177:218-228.

Biswas, A.K., Mohanty, M., Hati, K.M., and Misra, A.K. 2009. Distillery effluents effect on soil organic carbon and aggregate stability of a Vertisol in India. Soil Tillage Research 104:241-246.

Blanco-Canqui, H., and Lal, R. 2004. Mechanisms of carbon sequestration in soil aggregates. Critical Reviews in Plant Science 23:481-505.

Blanco-Canqui, H., Schlegel, A.J., and Heer, W.F. 2011. Soil-profile distribution of carbon and associated properties in no-till along a precipitation gradient in the central Great Plains. Agriculture Ecosystem Environment 144:107-116.

Chen, L., Zhang, J., Zhao, B., Yan, P., Zhou, G., and Xin, X. 2014. Effects of straw amendment and moisture on microbial communities in Chinese fluvo-aquic soil. Journal of Soils Sediments14:1829-1840.

Dameni, H., Wang, J.G., and Qin, L. 2010. Soil aggregate and organic carbon stability under different land uses in the North China Plain. Communications in Soil Science and Plant Analysis 41:1144-1157.

Gathala, M.K., Timsina, J., Islam, M.S., Rahman, M., Hossain, M.M., Harun-Ar-Rashid, I., et al. 2015. Conservation agriculture based tillage and crop establishment options can maintain farmers' yields and increase profits in South Asia's rice-maize systems: Evidence from Bangladesh. Field Crops Research 172:85-98.

Ghosh, B.N., Meena, V.S., Alam, N.M., Dogra, P., Bhattacharyya, R., Sharma, N.K., et al. 2016. Impact of conservation practices on soil aggregation and the carbon management index after seven years of maize-wheat cropping system in the Indian Himalayas. Agriculture Ecosystem and Environment 216:247-257.

Gwenzi, W., Gotosa, J., Chakanetsa, S., and Mutema, Z. 2009. Effects of tillage systems on soil organic carbon dynamics, structural stability and crop yields in irrigated wheat (Triticum aestivum L.) cotton (Gossypium hirsutum L.) rotation in semiarid Zimbabwe. Nutrition Cycle in Agroecosystem 83:211-221.

Kahlon, M.S., Lal, R., and Ann-Varughese, M. 2013. Twenty two years of tillage and mulching impacts on soil physical characteristics and carbon sequestration in Central Ohio. Soil and Tillage Research 126:151-158.

Karami, A., Homaee, M., Afzalinia, S., Ruhipour, H., and Basirat, S. 2012. Organic resource management: Impacts on soil aggregate stability and other soil physico-chemical properties. Agriculture Ecosystems and Environment 148:22-28.

Kemper, W.D., and Rosenau, R.C. 1986. Aggregate stability and size distribution. p. 425-442. In Klute, A. (ed.) Methods of soil analysis. Part 1. $2^{\text {nd }}$ ed. SSSA Book Series 5. American Society of Agronomy (ASA) and Soil Science Society of America (SSSA), Madison, Wisconsin, USA.

Kibet, L.C., Blanco-Canqui, H., and Jasa, P. 2016. Long-term tillage impacts on soil organic matter components and related properties on a Typic Argiudoll. Soil and Tillage Research 155:78-84. 
Kundsen, D., Peterson G.A., Pratt, P.F., and Page, A.L. 1982. Lithium, sodium, and potassium. p. 225-246. In Methods of Soil Analysis. Part 2. $2^{\text {nd }}$ ed. ASA and SSSA, Madison, Wisconsin, USA.

Kushwaha, C.P., Tripathi, S.K., and Singh, K.P. 2001. Soil organic matter and water-stable aggregates under different tillage and residue conditions in a tropical dryland agroecosystem. Applied Soil Ecology 16:229-241.

Liu, E., Saba, G., Yan, C., Yu, J., Gu, R., Liu, S., et al. 2014. Long-term effects of no-tillage management practice on soil organic carbon and its fractions in the northern China. Geoderma 213:379-384.

Martinez, I., Ovalle, C., Del Pozo, A., Uribe, H., Valderrama, N., Prat, C., et al. 2011. Influence of conservation tillage and soil water content on crop yield in dryland compacted Alfisol of central Chile. Chilean Journal of Agricultural Research 71:615-622.

Mikha, M.M., and Rice, C.W. 2004. Tillage and manure effects on soil and aggregate-associated carbon and nitrogen. Soil Science Society of America Journal 68:809-816.

Olsen, S.R., and Sommers, L.E. 1982. Phosphorous. p. 403-430. In Page, A.L., Miller, R.H., and Keeney, D.R. (eds.) Methods of soil analysis. Part 2. Chemical and Microbiological Properties. $2^{\text {nd }}$ ed. American Society of Agronomy, Soil Science Society of America, Madison, Wisconsin, USA.

Paul, B.K., Vanlauwe, B., Ayuke, F., Gassner, A., Hoogmoed, M., Hurisso, T., et al. 2013. Medium-term impact of tillage and residue management on soil aggregate stability, soil carbon and crop productivity. Agriculture Ecosystem and Environment 164:14-22.

Poirier, V., Angers, D.A., Rochette, P., Chantigny, M.H., Ziadi, N., Tremblay, G., et al. 2009. Interactive effects of tillage and mineral fertilization on soil carbon profiles. Soil Science Society of America Journal 73:255-261.

Rabbi, S.M.F., Tighe, M., Delgado-Baquerizo, M., Cowie, A., Robertson, F., Dalal, R., et al. 2015. Climate and soil properties limit the positive effects of land use reversion on carbon storage in Eastern Australia. Scientific Reports 5:17866.

Rajan, G., Keshav, R.A, Zueng-Sang, C., Shree, C.S., and Khem, R.D. 2012. Soil organic carbon sequestration as affected by tillage, crop residue, and nitrogen application in rice-wheat rotation system. Paddy and Water Environment 10:95-102.

Sandoval, M.A., Stolpe, N.B., Zagal, E.M., and Mardones, M. 2007. The effect of crop-pasture rotations on the C, N and S contents of soil aggregates and structural stability in a volcanic soil of south-central Chile. Acta Agriculturae Scandinavica Section B-Soil and Plant Science 57:255-262.

Sandoval-Estrada, M.N., Stolpe-Lau, E., Zagal-Venegas, M., Mardones-Flores, J., and Celis-Hidalgo, J. 2008. No-tillage organic carbon contribution and effects on an Andisol structure from the Chilean Andean foothills. Agrociencia 42:139-149.

Singh, V.K., Singh, Y., Dwivedi, B.S., Singh, S.K, Majumdar, K., Jat, M.L., et al. 2016. Soil physical properties, yield trends and economics after five years of conservation agriculture based rice-maize system in north-western India. Soil and Tillage Research 155:133-148.

Six, J., Feller, C., Denef, K., Ogle, S.M., Sa, J.C., and Albrecht, A. 2002. Soil organic matter, biota and aggregation in temperate and tropical soils-Effects of no-tillage. Agronomie 22:755-775.

Six, J., Paustian, K., Elliott, E.T., and Combrick, C. 2000. Soil structure and organic matter: I. Distribution of aggregate size classes and aggregate-associated carbon. Soil Science Society of America Journal 64:681-689.

Stone, L.R., and Schlegel, A.J. 2010. Tillage and crop rotation phase effects on soil physical properties in the west-central Great Plains. Agronomy Journal 102:483-491.

Tisdall, J.M., and Oades, J.M. 1982. Organic matter and water stable aggregates in soils. Journal of Soil Science 33:141-163.

Tripathi, S.K., Kushwaha, C.P., and Basu, S.K. 2012. Application of fractal theory in assessing soil aggregates in Indian tropical ecosystems. Journal of Forestry Research 23:355-364.

Tyler, S.W., and Wheatcraft, S.W. 1989. Application of fractal mathematics to soil water retention estimation. Soil Science Society of America Journal 53:987-996.

West, T.O., and Post, W.M. 2002. Soil organic carbon sequestration rates by tillage and crop rotation: A global data analysis. Soil Science Society of America Journal 66:1930-1946.

Xin, S., Zhu, A., Zhang, J., Yang, W., Xin, X., and Zhang, X. 2015. Changes in soil organic carbon and aggregate stability after conversion to conservation tillage for seven years in the Huang-Huai-Hai Plain of China. Journal of Integrative Agriculture $14: 1202-1211$

Yang, Z.P., Xu, M.G., Zheng, S.X., Nie, J., Gao, J.S., Liao, Y.L., et al. 2012. Effects of long-term winter planted green manure on physical properties of reddish paddy soil under a double rice cropping system. Journal of Integrative Agriculture 11:655-664.

Zhang, P., Wei, T., Jia, Z., Han, Q., Ren, X., and Li, Y. 2014. Effects of straw incorporation on soil organic matter and soil waterstable aggregates content in semiarid regions of northwest china. PLOS ONE 9:1-11.

Zhou, H., Lu, Y., Yang, Z., and Li, B. 2007. Influence of conservation tillage on soil aggregates features in North China Plain. Agricultural Sciences in China 9:1099-1106. 